\title{
Analysis of Affecting Factors of Graduate Education and Employment Xiu-Rong ZHANG
}

\author{
School of Maxism, China University of Geosciences (Beijing), \\ Haidian District, Beijing, 100083.
}

Keywords: Graduate student, Graduate education, Affecting factors, Employment.

\begin{abstract}
Based on the current situation of graduate education in China, this paper investigated the main factors that influence the quality of graduate education and the whereabouts of graduates. The graduation time, the graduate course average score, the amount of instructions received from their mentors and the quality of the graduate thesis significantly affect the whereabouts and employment of the students after graduation.
\end{abstract}

\section{Introduction}

With the increasing of the number of graduate students in China, the number of problems is arising, the students' comprehensive quality and personal abilities are also unevenly developed. A few of colleges and universities provide high quality educations, while others cannot fulfill China's rapid growing needs of graduate education. Especially after the 2008 global financial crisis, the ratio of graduate employment has decreased, which has brought unprecedented challenges to the limited educational sources and development of graduate educations. How to make the best of the training and teaching ability of the teachers and build productive relationship among mentors and students to improve the personal ability of graduate students are problems that need intensive study for graduate education providers. This paper, based on the current situation of graduate education in China, analyzed the main factors that affect the quality of graduate education and the whereabouts of graduates through empirical research, taking the data of a local university in China as the sampling pool, the statistical method taken by this paper was path analysis. The main goal of this research is to analyze and provide possible solutions for the problems of China's graduate education.

\section{The Present Situation and Problems of Graduate Education in China}

For now, the two main types of schooling of graduates in China include an academic degree awarded following a three-year graduate study and a two-year schooling promising of a major degree.

In the academic degree program, the first school year is spent by attending graduate courses, the second and third school year are the time for the student to join the entor's team to do scientific research capacity training and graduation thesis writing. The first school year of major degree schooling is also a time for graduate courses. In the second school year, students work under the guidance and directing from their mentors to do trainings focusing on practical skills and write their theses. The academic degree schooling pays more attention to the training of scientific research ability, while the major degree schooling pays more attention to the cultivation of practical occupation-oriented skills. The level of the research projects led or participated by the mentors as well as the situation of the mentors' actual work will directly affect the teaching quality and training effect of the graduate students. In most cases, in China the number of graduate students guided by one mentor is from 3 to 10 in the most extreme situation, it can be as high as nearly 20 . The disproportion of the numbers of mentors and students renders the mentors having less time and resources to direct their students one by one. It can also hamper the formation of a productive relationship among mentors and students. Since the number and quality of graduate students directly affect the academic reputation of colleges and institutes, most colleges and universities are expanding their enrollment and at the same time improving the quality of the graduate education. 
However, the improvement of the quality of education lags behind the graduate enrollment expansion. The number of enrollment is increasing every year, and the quality of graduate students is also obviously worse. The enrollment expansion is one of the main factors that affect the quality of graduate education.

This article investigated the academic training process of graduate students in a university in Beijing, China. The researchers studied the biographic data of the students, their grades of the degree course, the completion of their graduation thesis and the job choices after they left school. With the statistics software SPSS13.0, the path analysis is carried out on 300 people from a class of postgraduate students with three-year schooling of academic degree from 2016 to 2018 (the minimum sample number is according to the requirements of the software).The factors affecting the employment of Master graduate students are analyzed. The corresponding solutions are suggested in order to guide the design and carrying out of a more practical graduate education plan. This research also focused on helping the mentors to reach the full potential of their teaching capacity in order to improve the comprehensive quality of master graduate students.

\section{Research Design and Results}

Based on the years of experience in the management and schooling of graduate education in colleges and universities, taking the training program of the three-year graduate students as an example, researchers assumed that the main factors that affect the academic ability and future employment of graduate students are: (1) The students' graduate time (A1) which is divided into newly graduated and former year's graduated. Graduate course average score (A2), divided into average (average 60-79), good (average 80-89), excellent (average 90-100); Third, the ability of using English (A3), divided into average(not passed CET 4), good (passedCET4, but not passed CET6), excellent(passed CET6); The number of the team meeting weekly(A4), divided into high (more than 1 times per week), average (more than 1 times every two weeks), low (1 times every three or more than three weeks); Academic level of the program led and attended by the mentors(A5), including national level, provincial level, bureau level; and graduation thesis quality (A6), divided into average (average 60-79), good (averag 80-89), and excellent (average 90-100); what the students did after graduation(A7), divided into two categories: to continue their education or seek jobs.

The correlations between various factors and employment are shown in Table 1, "+" means "positive correlation". All the 13 hypotheses made by this research are listed below.

Hypothesis 1(H1) - graduate time (A1) is positively related to Graduate course average score (A2);

Hypothesis 2(H2) - graduate time (A1) is positively related to the ability of using English (A3);

Hypothesis $3(\mathrm{H} 3)$ - graduate time (A1) is positively related to the quality of graduation thesis (A6);

Hypothesis 4(H4) - graduate time (A1) is positively related to what the students did after graduation (A7);

Hypothesis 5(H5) - graduate course average score (A2) is positively related to the quality of graduation thesis (A6);

Hypothesis 6(H6) - graduate course average score (A2) is positively related to what the students did after graduation (A7);

Hypothesis 7(H7) - the ability of using English (A3) is positively related to the quality of graduation thesis (A6);

Hypothesis 8(H8) - the ability of using English (A3) is positively related to what the students did after graduation (A7);

Hypothesis 9(H9) - The number of the team meeting weekly (A4) and the quality of graduate thesis (A6) is positively correlated;

Hypothesis 10(H10) - The number of the team meeting weekly (A4) is positively related to what the students did after graduation(A7);

Hypothesis 11(H11) - Academic level of the program led and attended by the mentors (A5) is 
positively related to the quality of graduation thesis (A6);

Hypothesis 12(H12) - Academic level of the program led and attended by the mentors (A5) is positively related to what the students did after graduation (A7);

Hypothesis 13(H13)- graduation thesis quality (A6) and what the students did after graduation (A7) is positively correlated.

Table 1. Correlations among various factors

\begin{tabular}{|l|c|c|c|c|c|c|c|}
\hline Relevance & A1 & A2 & A3 & A4 & A5 & A6 & A7 \\
\hline A1 & & + & + & & & + & + \\
\hline A2 & + & & + & & & + & + \\
\hline A3 & + & + & & & & + & + \\
\hline A4 & & & & & & + & + \\
\hline A5 & & & & & & + & + \\
\hline A6 & + & + & + & + & + & & + \\
\hline A7 & + & + & + & + & & + & \\
\hline
\end{tabular}

According to the data and hypotheses, researchers established a model to analyze the correlations among the factors mentioned above, as shown in Figure 1.

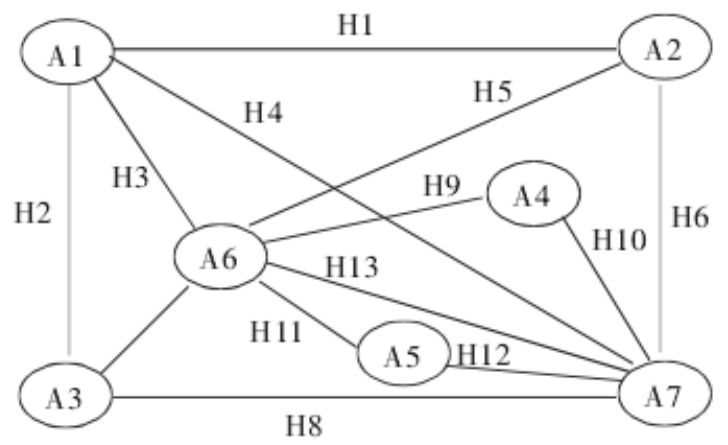

Fig 1. The model diagram of the correlation factors affecting what the students did after graduation.

The consistency reliability is tested by Cronbach $\alpha$ coefficient. Usually, the Cronbach $\alpha$ coefficient is greater than 0.65 , which is acceptable. After the reliability analysis with SPSS statistical software, the alpha values of each variable are above 0.65 , and the Cronbach $\alpha$ coefficient is shown in Table2, which indicates that the whole sample is in good consistency and the reliability of the data is very high.

Table 2. Cronbach $\alpha$ coefficient table

\begin{tabular}{|c|c|}
\hline Gauge & Cronbach a value \\
\hline A1 & 0.868 \\
\hline A2 & 0.687 \\
\hline A3 & 0.766 \\
\hline A4 & 0.753 \\
\hline A5 & 0.658 \\
\hline A6 & 0.876 \\
\hline A7 & 0.769 \\
\hline
\end{tabular}

The results of path analysis for the hypothetical model are shown in Table 3. According to the coefficient, 13 hypotheses are tested. 
Table 3. Path analysis results

\begin{tabular}{|c|c|c|c|c|c|}
\hline Hypothesis & $\begin{array}{c}\text { Relationship } \\
\text { between variables }\end{array}$ & $\begin{array}{c}\text { Normalized path } \\
\text { coefficient }\end{array}$ & Saliency & $\mathrm{t}(\mathrm{t}>1.96)$ & Result \\
\hline H1 & A1-A2 & 0.683 & $\mathrm{p}<0.001$ & 7.432 & Positive \\
\hline H2 & A1-A3 & 0.421 & $\mathrm{p}<0.01$ & 6.738 & Positive \\
\hline H3 & A1-A6 & 0.736 & $\mathrm{p}<0.001$ & 2.346 & Positive \\
\hline H4 & A1-A7 & 0.542 & $\mathrm{p}<0.001$ & 5.421 & Positive \\
\hline H5 & A2-A6 & 0.698 & $\mathrm{p}<0.001$ & 7.378 & Positive \\
\hline H6 & A2-A7 & 0.576 & $\mathrm{p}<0.001$ & 4.257 & Positive \\
\hline H7 & A3-A6 & 0.368 & $\mathrm{p}<0.01$ & 5.326 & Positive \\
\hline H8 & A3-A7 & 0.648 & $\mathrm{p}<0.001$ & 4.478 & Positive \\
\hline H9 & A4-A6 & 0.458 & $\mathrm{p}<0.001$ & 5.682 & Positive \\
\hline H10 & A4-A7 & 0.642 & $\mathrm{p}<0.001$ & 7.962 & Positive \\
\hline H11 & A5-A6 & 0.288 & $\mathrm{p}<0.01$ & 3.247 & Positive \\
\hline H12 & A5-A7 & 0.384 & $\mathrm{p}<0.01$ & 4.326 & Positive \\
\hline H13 & A6-A7 & 0.298 & $\mathrm{p}<0.001$ & 3.468 & Positive \\
\hline
\end{tabular}

\section{Result Discussion and Suggestive Solutions}

To sum up, through the above hypotheses and data analysis, it is reasonable to redact that:

(1) The graduate time has a strong influence on the graduate course average score, the quality of the graduation thesis and what the students did after graduate. Therefore, for the training of graduate students, the characteristics of the students should be fully fathomed and considered. The mentors make an appropriate training plan for them to reach their potential and better complete their graduate students' studies.

(2) Graduate course average score has certain influence on the quality of graduation thesis and the whereabouts after graduation. Let students fully realize that their learning attitude and willingness of doing academic research will play a positive role in their personal future development.

(3) The ability of using English also has a certain impact on the quality of graduation thesis and what the students did after graduation. The graduate students cannot lag their English ability behind during their study at school and improve the ability of English speaking. It also plays a key role in the future employment and development. Especially, the joint venture prefers employees being able to speak foreign languages.

(4) The number of instructions received from mentors weekly has an important influence on the quality of graduation thesis and the whereabouts of graduation. This should be paid more attention by the educational administration department and the mentors who cannot meet the students once per week. It is necessary to limit the number of students in order to establish a good relationship between teachers and students.

(5) The quality of the mentors' scientific research work also has a certain degree of influence on the quality of graduation thesis and the whereabouts of graduation, but it is not very significant. High level research projects will undoubtedly play a positive role in cultivating high-quality postgraduates. As mentors and scholars, high school employees should actively strive for high level scientific research projects.in order to provide the graduate students more and better opportunities to handle their schooling time, especially the cultivation of students' thinking ability and innovation ability.

(6) The correlation between the quality of graduation thesis and the whereabouts of graduation is very significant. In particular, some scientific research institutions and colleges and universities attach great importance to the students' scientific research and innovation ability. On one hand, the students who are committed to scientific research should develop their academic research ability in particular, and consciously cultivate their ability to engage in theoretical research and scientific and 
technological development independently. Complete the whole process of declaration, mid-term examination and concluding of related research projects, and make creative new achievements in science or technology. On the other hand, different employers have different requirements for graduate students, and enterprises generally focus more on practical work ability. Students engaged in technical management should pay attention to training the ability of design and operation, analysis and research, management and decision-making in order to be able to be competent for high level technology and management in the future. Some employers also pay attention to the work experience of graduate students. Ones that have worked before the graduate school will have more advantages.

\section{References}

[1] Li, L.; Wang, L. Y. AN EMPIRICAL STUDY ON THE EFFECT OF ECO- TOURISM VISITORS' ENVIRONMENTAL ATTITUDES ON ENVIRONMENTAL BEHAVIOR, J.Sci. APPLIED ECOLOGY AND ENVIRONMENTAL RESEARCH. 14 (2) 91-101.

[2] Li Lin, The Investigation and Analysis of College Students' Legal Awareness-a Survey with Beijing College Students as Subjects, PROCEEDINGS OF THE 2ND ANNUAL INTERNATIONAL CONFERENCE ON SOCIAL SCIENCE AND CONTEMPORARY HUMANITY DEVELOPMENT (SSCHD),Advances in Social Science Education and Humanities Research,2016( 73), 661-663.

[3] Odaci, Hatice; Kalkan, Melek, Problematic Internet use, loneliness and dating anxiety among $\begin{array}{lllll}\text { young adult } & \text { university }\end{array}$ EDUCATION Volume: 55 Issue: 3 Pages: 1091-1097 Published: NOV 2010 